\title{
A SOCIOLOGIA DOS MERCADOS \\ DE TRABALHO, ONTEM E HOJE*
}

NADYA ARAujo GUimarÃes

RESUMO

O interesse da sociologia pelos estudos do mercado de trabalho tem variado ao sabor dos desafios postos por distintas conjunturas históricas e dos debates intelectuais nelas travados. Este artigo procura acompanhar como se constituiu a moderna sociologia do mercado de trabalho, apontando as suas interfaces com outros domínios temáticos da sociologia e destacando sua importância para a formação de um pensamento latino-americano sobre a especificidade das nossas sociedades. Os debates da nova sociologia econômica arejaram a agenda e renovaram os instrumentos conceituais da sociologia dos mercados de trabalho, como mostra os resultados de estudo recente sobre o mercado de intermediação de oportunidades ocupacionais em São Paulo.

PALAVRAS CHAVE:Mercado de trabalho; sociologia econômica; intermediação de empregos; Brasil.

\section{ABSTRACT}

Sociological attention on labor market issues varies among social contexts and intellectual approaches. The article focuses on the emergency of a sociology of labor markets, on its interfaces with other domains, and stresses its importance for the debate during the 1960's and 70's on the specificity of Latin American contemporary societies. It argues that the new economic sociology agenda and its conceptual tools have been renewing the sociology of labor markets traditional approach and illustrates this argument with recent research results on the search for job, labor market intermediaries and labor offer-demand match under flexible markets like São Paulo.

KEYWORDS: Labor market; economic sociology; labor market intermediaries; Brazil

\section{DE VOLTA AO MERCADO}

[*] Exposição proferida por ocasião do concurso para professora titular do Departamento de Sociologia da Universidade de São Paulo, área de Sociologia do Trabalho. São Paulo, 8 dez. 2008 .
Tem sido crescente o interesse da sociologia brasileira pelos estudos do mercado de trabalho e das formas e experiências associadas ao desemprego, depois de um longo período de jejum intelectual durante o qual haviam dominado as análises sobre as condições de organização e uso do trabalho no cotidiano das empresas e sobre as formas da ação coletiva sustentada pelos sindicatos. 
Não sem razão, se pensarmos queestamos tratando de um ramo da sociologia fortemente pautado pelos desafios da agenda social. Nesta, os recentes processos de reestruturação macroeconômica e microorganizacional tiveram efeitos importantes, não apenas no que tange às relações sociais nos locais de trabalho, como também no mercado de trabalho. Ali, eles ampliaram o volume e a duração do desemprego, diferenciando as suas formas e diversificando as modalidades de ocupação e de relações contratuais de trabalho. Nesse contexto, não apenas o desemprego reencarnava o seu papel de importante mecanismo de redistribuição das oportunidades ocupacionais entre os trabalhadores ativos, como as próprias alternativas de trabalho revelavam-se agora mais nítidas em sua diversidade.

O movimento que leva do trabalho ao desemprego passou a ser, então, mais e mais esquadrinhado pela sociologia brasileira. Destacavam-se os estudos sobre o risco desigual com que a perda do trabalho atingia certos grupos de indivíduos, distintos por características tais como idade, sexo, cor, posição na família, momento no ciclo de vida, escolaridade, ocupação e setor de atividade. Ao lado desses estudos, fizeram-se mais freqüentes as análises longitudinais de tipo quantitativo sobre trajetórias de desempregados, não raro aliadas a (e/ou alimentando) pesquisas qualitativas sobre representações subjetivas acerca da experiência da perda da ocupação regular.

O mercado de trabalho voltava, assim, a estar no centro do interesse sociológico em geral e da ciência social brasileira, em especial. Mais ainda: o trabalho, aquele que fora denominado "um valor em vias de desaparição", parafraseando Méda를 cujas idéias ecoaram com enorme sucesso o argumento de Offe, surpreendia-nos pelo vigor da sua presença no imaginário social. Ter trabalho, manter o trabalho, viver do trabalho estavam no centro das percepções, das motivações e dos sentimentos flagrados em diversas pesquisas de opinião que investigaram atitudes dos brasileiros na década de 1990.

Entretanto, não se pode perder de vista que as idas e vindas do interesse da sociologia pelo tema do mercado de trabalho desvelam modos de apreensão distintos, que desnudam aspectos diversos do campo, atiçados por desafios sociais datados, porque peculiares às suas épocas respectivas, e por interlocutores intelectuais igualmente enraizados em conjunturas e debates específicos.

Tento isso em mente, iniciarei este texto tratando da incerta trajetória de vigência intelectual da categoria "mercado de trabalho", destacando as suas idas e vindas no cenário do debate acadêmico da sociologia nas últimas décadas. Em seguida, procurarei me deter sobre o revigoramento atual dos estudos sociológicos no tema.

Ordenando a narrativa, lançarei mão de dois recursos. De um lado, a releitura aqui proposta se organizará de maneira a apresentar e bem
[1] Méda, D. Le travail: une valeur en voie de disparition. Paris: Aubier, 1995. 
[2] Kalleberg,A.e Sorensen,A. "The sociology of labor markets". Annual Review of Sociology, vol. 5, 1979, pp. 351-79.

[3] Caplow, T. The sociology of work. Nova York: McGraw- Hill, 1954.

[4] Erbes- Séguin, S. La sociologie du travail. Paris: La Découverte, 1999.

[5] Freidmann, G. e Naville, P. (orgs.). Traité de sociologie du travail. Paris: A. Colin, 1962. usufruir as discussões teóricas travadas pela sociologia econômica contemporânea, de todo oportunas para fertilizar a agenda empírica da sociologia do trabalho. De outro lado, e sempre que cabível, tratarei de inocular nos meus argumentos um sopro de vida pelo uso seletivo de achados recentes de pesquisa.

\section{A SOCIOLOGIA DOS MERCADOS DE TRABALHO}

Não seria descabido dizer, secundando Kalleberg e Sorensen², que o campo de estudos dos mercados do trabalho se estruturou inicialmente como uma área de confluência entre diferentes linhagens e tradições acadêmicas, provenientes da estratificação social, da sociologia das ocupações, da sociologia industrial, da sociologia das organizações e, como não poderia deixar de ser, da economia do trabalho.

Retomando argumentos, como os de Caplow (expresso em manual de estudos sobre sociologia do trabalho que circulou nos Estados Unidos nos anos de 1950), vemos que a legitimidade deste campo era então argüida com base numa característica típica das sociedades capitalistas do pós-guerra: era do mercado de trabalho que a ampla maioria das pessoas retirava a sua sobrevivência, nele obtendo não apenas os seus salários, mas toda uma gama de outras vantagens indiretas. O mercado constituía-se, assim, no mecanismo central de distribuição social, sendo, por isso mesmo, uma arena incontornável para os que se propusessem a explicar a produção de desigualdades nas sociedades industriais.

No mundo francês, as formulações pioneiras deixavam entrever o lugar relativamente secundário que tinham os estudos sobre mercado de trabalho, ao menos quando comparados às análises da organização do trabalho ou das formas de ação coletiva. Assim, Erbes-Séguin 4 , refletindo sobre a trajetória da constituição da sociologia do trabalho na França, não encontra lugar para os estudos do mercado de trabalho entre os grandes temas que identifica como "tradicionais" à disciplina.

Essas primeiras abordagens punham ênfase em aspectos relativos à circunscrição geográfica, setorial, ocupacional do mercado, ou mesmo referindo-o a segmentos sociais particularizados por sua idade, etnia ou escolaridade. Dessa forma, uma passada d'olhos no mais importante manual de sociologia do trabalho no mundo francês de então, o Traité de sociologie du travail, organizado por Georges Freidmann e Pierre Navilles, revela que toda a segunda das cinco partes em que se organiza o manual está dedicada aos elos entre "Industria, População e Emprego".

Nela, uma teoria sociológica do emprego, e porque não dizer do emprego industrial, reina com toda a precedência analítica. $O$ mercado de trabalho vem à luz por meio de temas como o desemprego ou 
como a orientação e a formação profissionais que dariam aos indivíduos as condições de empregabilidade (para usar o conceito cunhado pouco depois por Ledrut ${ }^{6}$ ). Mas é a abordagem da "distribuição da população", tal como ali denominada, aquela a que se dedica maior extensão nesta segunda parte. Ou seja, é a compreensão, certamente ainda pouco refinada, do mercado de trabalho pela lente da sua composição sociodemográfica (por sexo, idade, grupos étnicos e nacionais) que dá a tônica à análise.

Essas primeiras maneiras de abordar cederam progressivamente lugar a conceituações mais abstratas e relacionais, como aquela posteriormente sugerida por Kalleberg e Sorensen, nos anos de 1970, para quem o mercado de trabalho seria mais propriamente "uma arena na qual os trabalhadores trocam a sua capacidade de trabalho por salários, status e outras recompensas [...], compreendendo as instituições e as práticas que governam a compra, a venda e a fixação de preço do trabalho"7.

No mundo anglo-saxão, quatro grandes temas constituíram, neste momento, o veio principal da produção acadêmica dedicada ao mercado de trabalho:(i) estudos sobre desigualdades na retribuição auferida pelo trabalho; (ii) estudos sobre carreiras e mobilidade; (iii) análises sobre a segmentação existente entre subpopulações; e (iv) análises sobre mudança social e estrutura dos mercados de trabalho ${ }^{8}$. Tal agenda deixava entrever o diálogo que já se estabelecia com a economia mais ortodoxa, ou, quando menos, o olhar desconfiado que os sociólogos lançavam em direção a supostos caros aos economistas de então, como os da permeabilidade, homogeneidade e transparência, que acreditávamos ser de duvidosa aplicabilidade àquele mercado por onde circulava a força de trabalho.

Mas, e como sublinhariam posteriormente Fligstein e Dauter9, esta agenda teve como grande ponta-de-lança, até os anos de 1970, os estudos sobre aquisição de status. De fato, uma das indagações fundadoras do interesse sociológico de então remetia à descrição e à análise das diferenças sociais entre os indivíduos, manifestas na desigual distribuição de prestígio e poder. Como expressar tais diferenças, e, naturalmente, como explicá-las, era algo que desafiava os intérpretes.

Para eles, o status social (isto é, as diferenças de posição social relativa que distinguiriam entre si indivíduos ou grupos sociais) poderia se fundar em uma multiplicidade de determinantes. Entre eles, a ocupação constituía-se num indicador de valor estratégico. A situação no mercado de trabalho, operacionalizada via situação ocupacional — com o prestígio social a ela associado - , mostrava-se, então, uma das mais poderosas medidas de posição nas hierarquias de status social. Por isso mesmo, a mobilidade ocupacional interessava sobremaneira a esses teóricos, na medida em que se configurava em um dos cami-
[6] Ledrut, R. La sociologie du chômage. Paris: Presses Universitaires de France, 1966.

[7] Kalleberg e Sorensen, op. cit., p. 351 .

[8] Ibidem.

[9] Fligstein, N. e Dauter, L. "The sociology of markets". Annual Review of Sociology, vol.33, 2007, pp.105-138. 
[10] Bendix, R. e Lipset, S. M. (eds.). Class, status, and power: social stratifcation in comparative perspective. $2 \mathrm{ed}$. Nova York: The Free Press, 1966; Lipset, S. M.e Bendix, R.Social mobility in industrial society. Berkeley: University of Califórnia Press, 1959; Blau, P. e Duncan, O.D.The american occupational structure. Nova York: Wiley, 1967.
[11] Destacam- se, entre os clássicos dos anos de 1960, os estudos de $\mathrm{Hu}$ tchinson, B. e outros.Mobilidade e trabalho. Rio de Janeiro: Centro Brasileiro de Pesquisas Educacionais, 1960; Hutchinson, B. "Urban mobility rates in Brazil related to migration and changing occupational structure". América Latina, $\mathrm{n}^{\circ}$ 5, 1962, pp. 3- 20; Moreira Jr., R. "Educação, estratificação e mobilidades sociais no Brasil". In: Moreira Jr.. Educação e desenvolvimento no Brasil. Rio de Janeiro: Centro Latino-Americano de Pesquisas em Ciências Sociais, 1960; Kahl, J. "Urbanização e mudanças ocupacionais no Brasil". América Latina, ${ }^{\circ}{ }^{5,1962,}$ pp. 196-223; Gouveia, A. J. "Desenvolvimento econômico e prestígio de certas ocupações". América Latina, $\mathrm{n}^{\circ}$ 9, 1965, pp. 66-78. nhos mais eficazes para a aquisição de status. Dito de outro modo, a mobilidade ocupacional importava por ser tida como a avenida, por excelência, da mobilidade social ${ }^{10}$.

Desafiava-os, assim, entender como os indivíduos se distribuíram em um conjunto finito de posições, de acordo com características pessoais como origem familiar, educação, sexo ou raça. Nesse sentido, o mercado de trabalho e sua dinâmica eram observados antes pelo lado da oferta, e pouca atenção era dada à dinâmica da firma, cabendo mais propriamente aos economistas os avanços mais importantes na teorização acerca dos mercados internos e externos de trabalho, ou mesmo a mensuração das formas de segmentação ocupacional.

Se a agenda de estudos pouco a pouco se adensava e diversificava, no entrecruze de influências das diversas linhagens com as quais se dialogava, é também verdade que ela estava aderida aos desafios sociais do capitalismo em expansão nos seus "anos dourados" após a Segunda Guerra Mundial. Ela carregava consigo o olhar sobre o mercado de trabalho e as suas desigualdades, refletindo a experiência da constituição de sociedades industriais em países de capitalismo originário.

Mas, uma sociologia do mercado de trabalho latino-americano carecia forjar uma agenda que lhe fosse própria, que se revelasse capaz de dar conta das especificidades dos chamados "mercados heterogêneos de trabalho". Tal foi o desafio de uma geração de teóricos que, nos anos de 1960 e 1970, não somente renovou o debate sobre a noção de mercado de trabalho, como articulou-o de maneira indissociável à questão do desenvolvimento.

\section{MERCADO DE TRABALHO E DESENVOLVIMENTO LATINO-AMERICANO: AS NOVIDADES DOS ANOS DE 1960 E 1970}

Quando perseguimos, no pensamento sobre a América Latina, as pistas da constituição de uma sociologia do mercado de trabalho logo vemos que, também aqui, as análises sobre a mobilidade ocupacional se constituíram no território pioneiro. E não por acaso esse tema repercutia tanto entre nós, latino-americanos em geral e brasileiros em especial ${ }^{11}$.

As hipóteses sobre a mobilidade social estiveram na raiz de algumas das mais importantes explicações para os processos de "modernização", para retomarmos conceito caro ao jargão acadêmico de corte funcionalista, então hegemônico. Tais estudos mostravam especial interesse por entender as transformações das hierarquias sociais, expressas justamente em mudanças na estrutura ocupacional e na conseqüente emergência de novos grupos sociais; ou, dito de modo mais afeito ao estilo da época, havia que explicar as chances de aparecimento, nesses países, então denominados "tradicionais", dos grupos 
sociais que haviam forjado os arranjos societários típicos dos países ditos "modernos", ou de desenvolvimento capitalista originário ${ }^{12}$.

As análises da mobilidade social, sustentadas nos estudos da mobilidade ocupacional, foram também precursoras, na sociologia brasileira, das indagações de tipo longitudinal. Assim, os estudos dos anos de 1950 e 1960 foram insistentes em suas preocupações acerca dos caminhos da mobilidade intergeracional, tratados via de regra à luz dos percursos ocupacionais e escolares de pais efilhos. Por meio deles, buscava-se antever, nos trajetos ascendentes, a permeabilidade da estrutura social à mudança pela via da fluidez do seu sistema de estratificação ${ }^{13}$.

O trabalho - e, nele, o mercado de trabalho, arriscaria dizer - estava longe de ser um território de interesse analítico que lhes importasse em si mesmo. Ele provia, antes, os indicadores empíricos para um fenômeno de outra natureza — o da constituição das hierarquias de estratificação social (aí contidas as indagações sobre mobilidade social) —, este, sim, central às teorias sociológicas do desenvolvimento.

Não sem razão, aqueles que hoje consideramos os fundadores da moderna sociologia do trabalho no Brasil circunscreviam os seus próprios escritos e avanços analíticos ao campo de estudos do desenvolvimento e da modernização, antes que ao campo de uma sociologia do trabalho, e menos ainda ao de uma sociologia dos mercados de traba1ho'14. Mas uma e outra - sociologia do trabalho e sociologia dos mercados de trabalho - já estavam ali esboçadas, e de modo bastante rico.

Curiosamente, os estudos sociológicos que se reivindicavam como interessados no mercado de trabalho, ao se consolidarem, relegaram o foco longitudinal que tanto atraíra as teorias da estratificação (e da mobilidade) e que tão importante se tornaria nas análises contemporâneas sobre a dinâmica do mercado de trabalho. Centraram-se, antes, no entendimento da estrutura do emprego e nas comparações entre diferentes descrições de tipo cross-section, como forma de bem refletir sobre as mudanças no mercado de trabalho correlatas à urbanização e à industrialização crescentes ${ }^{15}$.

Mas, foram as análises de inspiração marxista ${ }^{16}$, sobre a assim chamada "marginalidade social", o grande divisor de águas nos estudos do mercado de trabalho. A elas devemos o esforço sociológico no sentido de teorizar de maneira sistemática acerca da particular heterogeneidade que caracterizaria o trabalho na América Latina. ${ }^{17}$

O debate em torno da categoria "marginalidade" agitava os meios intelectuais latino-americanos desde o final dos anos de 1960, com destaque para os primeiros textos do peruano Anibal Quijano ${ }^{18}$. Logo se consolidaria como o tema da vez. Quase que simultaneamente aos escritos de Quijano, em 1969, surge outro artigo, também seminal e também veiculado no meio intelectual chileno; de autoria do argentino Jose Luis Nun, prossegue com a reflexão acerca da pertinência da
[12] Hagen, E. On the theory of social change: how economic growth begins. Homewood: Dorsey Press, 1962; Eisenstadt, S. Modernization, protest and change. Englewood Cliffs, NJ: Prentice- Hall, 1966; McClelland, D. The achieving society. Princeton, NJ: Van Nostrand, 1971; Parsons, T. The social system. Londres: Routledge \& Kegan Paul, 1952; Germani, G. Sociologia da modernização. São Paulo: Mestre Jou, 1974.

[13] Hutchinson e outros, op. cit.; Hutchinson, op. cit.; Gouveia, op. cit.

[14] Lopes, J. Sociedade industrial no Brasil. São Paulo: Difusão Européia do Livro, 1965; Idem. A crise do Brasil arcaico. São Paulo: Difusão Européia do Livro, 1967.

[15] Bazzanella, W. "Estratificação e mobilidade social no Brasil: fontes bibliográficas". Rio de Janeiro: Centro Brasileiro de Pesquisas Educacionais, 1956; Idem, "Problemas de urbanização na América Latina: fontes bibliográficas". Rio de Janeiro: Centro Brasileiro de Pesquisas Educacionais, 1960; Costa Pinto, L. A. e Bazzanella, W.Processos e implicações do desenvolvimento. Rio de Janeiro: Zahar, 1969; Lopes. Desenvolvimento e mudança social. São Paulo: Editora Nacional/Editora da Universidade, 1968; Madeira, F. e Singer, P. I. "Estrutura do emprego e trabalho feminino no Brasil". Caderno Cebrap, no 13, 1975; Faria, V. E. Occupational marginality, employment and poverty in urban Brazil. Cambridge, Mass, PhD dissertation, Harvard University, 1976.

[16] Ou "histórico- estruturais", como por vezes elas mesmo se denominavam.

[17] Uma história mais rigorosa do debate latino- americano certamente terá que dar créditos à formulação inicial do Desal, instituição religiosa atuante no Chile, e aos escritos do seu ideólogo principal, Roger Vekemans (ver Vekemans, R. e Venezas, R. "Marginalidad, incorporación e integración”. Santiago: Desal, 1966 , mimeo.), notadamente ao livro Marginalidad en América Latina : un ensayo de diagnostico (Barcelona: Herder, 1969). A esse respeito, ver Castro, N. A. Ejército de reserva: su especificidady comportamiento político en el desarrollo del capitalismo en Brasil. México, tese de doutorado, Universidad Nacional Autónoma de México, 1983. 
[18] Quijano veiculara um primeiro texto, que logo se tornou referência no trato do tema: "Notas sobre el concepto de 'marginalidad social"'. Santiago: División de Asuntos Sociales/Cepal, 1966, mimeo. A repercussão alcançada levou Quijano a participar de uma coletânea que marcou época nos estudos latino- americanos: Quijano, A. "Urbanización, cambio socialy dependencia". In: Cardoso, F. H e Weffort, F. (eds.).America Latina: ensayos de interpretación sociológica Santiago: Editorial Universitaria, 1967. Ver também do autor: "La formación de un universo marginal en las ciudades de América Latina".In:Castells, M.(org.).Imperialismo y urbanización en América Latina. Barcelona: Gustavo Gili, 1973.

[19] Nun, J. L. “Sobrepoblación relativa, ejército industrial de reserva y masa marginal". Revista Latinoamericana de Sociología, vol. 5, n. 2, 1969. Neste artigo o autor dá andamento ao argumento que começara a delinear com Marin e Murmis em um manuscrito de 1967 (Nun, J. L., Marin, J. C. e Murmis, M. "Planteo general de la marginalidad en América Latina", Santiago, 1967, mimeo.).

[20]DiPrete, T. e Nonnemaker, K. "Structural change, labor market turbulence and labor market outcomes". Durham: Duke University, 1996, mimeo.; Elias, P. “Occupational change in a working- life perspective: internal and external views". In: Penn, R., Rose, M. e Ruberry, J. (eds.). Skill and occupational change. Oxford: Oxford University Press, 1994, pp. 75- 105; Idem, "Reestruturação, requalificação e dispensas: um estudo da dinâmica do mercado de trabalho do Reino Unido, 1991- 95". Dados, 2004, vol. $47, \mathrm{n}^{\circ} 3$, pp. 419- 71 .

[21] O ensaio de Francisco de Oliveira ("A economia brasileira: crítica à razão dualista". Estudos Cebrap, $\mathrm{n}^{\circ}{ }_{2}$, out., 1972) tornou-se referência obrigatória no debate. Oliveira voltaria ao tema outras vezes, especialmente num outro texto que também marcou época: "A produção dos homens sobo capital". Estudos Cebrap, n 16, 1976.

[22] Coube a Oliveira trazer tal discussão para o centro da explicação sobre o caráter do desenvolvimento capitalista no Brasil e sobre a natureza da aliança política de classes e da forma de gestão do Estado em que tal desenvolvimento se sustentava. categoria "massa marginal" ${ }^{19}$. Nun argüia a especificidade dos processos de produção da superpopulação relativa em países periféricos, sob o capitalismo monopolista, mostrando que parte dela deixara de cumprir a função de um exército de reserva para a produção capitalista, tal como preconizara Marx ao analisar a dinâmica do mercado de trabalho sob o capitalismo concorrencial.

É curioso observar que o enfoque das teorias da marginalidade trouxe consigo, de precursor, a idéia da "redundância", que reapareceria posteriormente, com vigor, em certas tendências de interpretação do emprego em contextos de intensa reestruturação nos países capitalistas centrais ${ }^{20}$.

Francisco de Oliveira, em seu clássico ensaio "Aeconomia brasileira: crítica à razão dualista", divulgado em 1972, entraria na discussão, refinando-a teórica e historicamente e situando o debate sobre as formas de incorporação econômica e política dos trabalhadores no terreno dos elos entre modalidades de crescimento capitalista e de alianças de classe, e trazendo a política para o centro da análise ${ }^{21}$. Esse ensaio já deixava entrever que a discussão também pautava o debate no Brasil, e com muita força. E que não se tratava de um tema restrito apenas aos estudiosos do urbano e do trabalho, onde por certo ele tinha centralidade ejá vinha se desenvolvendo desde alguns anos ${ }^{22}$.

Com efeito, entre os estudiosos da urbanização brasileira, tema desafiador dos intérpretes das mudanças em curso no Brasil dos anos de 1960 e 1970, a problemática da assim chamada "marginalidade urbana" estava solidamente estabelecida como central à agenda de pesquisa. Havíamos abandonado as idéias sobre o caráter "sociopático" do nosso processo de crescimento urbano ${ }^{23}$, pondo ênfase na funcionalidade das formas de inserção não tipicamente capitalistas para o entendimento da dinâmica do emprego nas nossas grandes cidades e para o processo de acumulação capitalista no Brasil. Os escritos de Luis Antonio Machado da Silva, Manuel Berlinck, Lucio Kowarick, Vilmar Faria eram exemplos de como se debruçava sobre o tema nossa inteligenzia ${ }^{24}$.

A crítica à razão dualista nutriu-se do esforço por evidenciar como a reprodução das formas não-capitalistas de trabalho era parte constitutiva das necessidades do desenvolvimento do capital, para usarmos o linguajar daquele momento; ou, como as formas não-capitalistas de produção e de trabalho eram funcionais (para usarmos outra categoria que melhor evidencia a lógica de argumentação) à reprodução do capital 25 .

Estes estudos documentaram de maneira primorosa a heterogeneidade e a instabilidade da inserção ocupacional dos indivíduos, deixando assente, e de modo cabal, que o processo de transformação que nossos países experimentavam estava longe de se ajustar a hipóteses providas pelas teorias (lineares) da modernização ${ }^{26}$. 
No bojo do mesmo movimento intelectual, as análises sobre condições de reprodução da classe trabalhadora ${ }^{27}$ desafiavam os resultados encontrados nos países capitalistas de desenvolvimento originário, pondo em xeque a crença de que o mercado devesse ser o único mecanismo de alocação de recursos e de distribuição social. Ao contrário, elas destacavam como outras instituições - a família, os grupos de vizinhança e as redes de sociabilidade - cumpriam papel primordial no entendimento das condições de vida e das formas de inserção no trabalho. Estas, via de regra, se equacionavam tendo muito especialmente o grupo familiar como arena de construção de estratégias em face da pobreza, sobretudo pela via da alocação de seus membros ao mercado de trabalho. Nos cotidianos da família, conforme tão bem demonstraram Lobo, Abreu e Hirata ${ }^{28}$, e pelas teias da socialização de meninos e meninas, as relações sociais de gênero fincavam as estacas da divisão social do trabalho, que repercutiriam no mercado e nos locais de emprego.

Finalmente, as análises conduzidas entre fins dos anos de 1950 e início da década de 1970 por autores como Lopes e Rodrigues ${ }^{29}$, entre outros, davam conta da importante segmentação regional do mercado de trabalho brasileiro, ainda carente de uma efetiva nacionalização. As estratégias individuais, mormente expressas na migração para os grandes centros industriais, não somente deixavam entrever a importância dos elos com os locais de origem, como também a efetiva pendularidade do movimento de ir evir, compensando refluxos da atividade no local de acolhida. Se o processo de nacionalização do mercado de trabalho tivera início com Vargas, com seu ícone na chamada "Lei dos Dois Terços", somente nos anos de 1980 ele viria a se completar com o efetivo enraizamento de uma força de trabalho "livree despossuída", para tomar de empréstimo as palavras de Marx, que se defrontaria, então, com a primeira grande crise de desemprego em massa, agora, sim, retida nas grandes metrópoles.

Eram, assim, outras - e novas - as trilhas do processo de constituição de uma força de trabalho e de um mercado de trabalho nacionais. Desafiava-nos teorizar o processo de construção social deste mercado. Entretanto, e justamente quando a reflexão teórica nos deixava de braços com evidências cabais e estudos seminais que nos permitiriam fazê-lo, voltamo-nos, sociólogos do trabalho, para o interior das fábricas, para o estudo dos processos de trabalho, especialmente interessados nos ambientes fabris e na dinâmica das relações sociais no interior das firmas.

O mercado de trabalho, mais uma vez, passava ao fundo da cena. Quando muito, era o fundamento para descrições sobre o regime de subordinação do trabalho, como mostraram Ferrante, em seu estudo de caso, e Marini nas suas formulações mais gerais ${ }^{30}$. Ele reaparecia
[23] Ao modo de Luiz Pereira.Trabalho e desenvolvimento no Brasil. São Paulo: Difusão Européia do Livro, 1965.

[24] Machadoda Silva,L.A.Mercados metropolitanos de trabalho manual e marginalidade. Rio de Janeiro: dissertação de mestrado, Universidade Federal do Rio de Janeiro, Programa de Pós- Graduação em Antropologia do Museu Nacional, 1971; Berlinck, M. Marginalidade social e relações de classe em São Paulo. Petrópolis: Vozes, 1975; Kowarick, L. Capitalismo e marginalidade na América Latina. Rio de Janeiro: Paz e Terra, 1975; Faria, op. cit.

[25] Kowarick, op. cit.; Berlinck, op. cit.; Fausto Neto,A.M.Q.Família operária e reprodução da força de trabalho. Rio de Janeiro: Vozes, 1982; Bilac, E. D. Famílias de trabalhadores - estratégias de sobrevivência: a organização da vida familiar em uma cidade paulista. São Paulo: Edições Símbolo, São Paulo,1978; Prandi,J.R.Otrabalhadorpor conta própria sob o capital. São Paulo: Edições Símbolo, 1978.

[26] Ao modo de Hagen. op. cit.; Eisenstadt, op. cit.; McClelland, op. cit.

[27] Ver Bilac, op. cit., e Fausto Neto, op. cit., entre outros.

[28] Lobo, E. S. "Expériences de femmes, destin de genre". Actes. Atelier/ production/reproduction. Paris, vol. 2, $\mathrm{n}^{\circ}$ 7, pp. 205-16, 1988; Abreu. A. Trabalho industrial a domicilio na indústria de confecção. São Paulo: tese de doutorado, Universidade de São Paulo, 1980; Hirata, Helena. Nova divisão sexual do trabalho? Um olhar voltado para a empresa e a sociedade. São Paulo: Boitempo, 2002.

[29] Lopes, Sociedade industrial no Brasil, op. cit.; Rodrigues, L. M. Industrialização e atitudes operárias. São Paulo: Brasiliense, 1970.

[30] Ferrante,V.B.FGTS:Ideologia erepressão. São Paulo:Ática, 1978; Marini, R. M. Subdesarrollo y revolución. México: Siglo XXI, 1970; Idem. Dialéctica de la dependência. México: Era, 1977. 
[31] Noronha, E. G. Entre a lei e a arbitrariedade: mercados e relações de trabalho no Brasil. São Paulo: LTr, 1999; Idem. "O modelo legislado de relações de trabalho no Brasil". Dados, vol. 43, nº 2, 2000; Arbix, G.Uma aposta no futuro: os primeiros anos da câmara setorial da indústria automobilistica. São Paulo: Scritta, 1995; Cardoso, A. M. Nas teias da modernidade: pragmatismo sindical e democratização do Brasil. São Paulo: tese de doutorado, FFLCH/USP, 1995.
[32] Swedberg, R. "Markets as social structures". In: Smelser e Swedberg, R. (eds). The handbook of economic sociology. Princeton: Princeton University Press, 1994, cap. 11, pp. 255- 82; Fligstein, N. "Markets as politics: a political cultural approach to market institutions". American Sociological Review, vol.61,pp. 656-73,1996; Fligstein. N. e Dauter. L. op. cit.; Steiner, P. La sociologie économique. Paris: La Découverte, 1999; Idem, "Le marché vu par la sociologie économique". Lille, 2004, mimeo.

[33] Claro que aqui retomo, como inspiração, o argumento de Max Weber para figurar o encanto da dinâmica dos mercados para a imaginação do sociólogo (Economía y sociedad: esbozo de sociología compreensiva. México: Fondo de Cultura Económica, 1961). pontualmente como mecanismo de sustentação para o despotismo fabril que andava junto com o despotismo político do período ditatorial. Ele se pautava por novas normas que incrementavam a fragilidade dos vínculos, regulando a rotação dos trabalhadores que se tornaria intensa no período ditatorial (pelas vias da extinção do instituto da estabilidade e da criação do Fundo de Garantia por Tempo de Serviço, por exemplo). Ao passo que se retraía a sociologia dos mercados de trabalho, consolidava-se uma ciência política do trabalho, que tinha no estudo das regulações deste mercado um dos seus alvos ${ }^{31}$.

\section{POR UMA SOCIOLOGIA (ECONÔMICA) DOS MERCADOS DE TRABALHO}

Mas, por que nos faria falta uma sociologia (econômica) dos mercados de trabalho? Ou, dito de outra forma, como a análise destes se beneficiaria das reflexões da sociologia econômica contemporânea acerca dos mercados em geral e da circulação do trabalho em especial?

Para a sociologia econômica, teorizar sobre o funcionamento dos mercados, assim como das firmas, destacando os mecanismos sociais (extra-econômicos) que pautam a sua construção foi um domínio privilegiado desde a primeira hora; e não sem razão, posto serem mercados e firmas dois dos focos centrais às teorias (formuladas por sociólogos e por economistas) relativas à dinâmica da vida econômica ${ }^{22}$. Já para a sociologia do trabalho, e como vimos antes, o mercado de trabalho seguiu por muito tempo sendo um âmbito estudado mais pelos seus resultados (ou, para usar o termo caro aos economistas, sua "estrutura"), do que pelos processos que nele tinham lugar.

A insuficiência desse último olhar não deixaria de se fazer sentir mais cedo ou mais tarde. Era preciso esclarecer pelo menos dois aspectos cruciais a um olhar sociológico e de há muito sugeridos por Max Weber. Eles poderiam ser mais bem expressos em duas indagações. Por que, em face de uma pluralidade de possibilidades de troca entre agentes, uma - e apenas uma - se torna efetiva33? Quais seriam os mecanismos mobilizados pelos agentes no seu esforço por transformar o pressuposto da infinidade de trocas potenciais no resultado final em que apenas uma dessas trocas se consumaria? Ora, o mercado por onde circulava a assim chamada "mercadoria força de trabalho" certamente não estaria livre do desafio analítico aberto por esse tipo de abordagem.

Os economistas habitualmente responderam a esse desafio recorrendo às suas funções de preço e produtividade e ao cruzamento entre ambas, cuja condição de possibilidade estava ancorada no suposto da racionalidade da conduta dos agentes econômicos. Assim, $\mathrm{o}$ " $\mathrm{x}$ " do problema estaria na convergência de interesses em torno do preço pelo qual um trabalhador qualquer aceitaria vender o trabalho 
(ou comprá-lo, se tomarmos o ponto de vista do empresário), dada a produtividade suposta (encarnada num certo quantum de capital humano) que possui (ou que se necessita adquirir, incorporando ao negócio, novamente se o prisma for aquele do empresário que recruta).

Foi dessa maneira, ao mesmo tempo simples e elegante, que os economistas resolveram o problema analítico do encontro entre demandantes de emprego e ofertantes de oportunidades de trabalho. Entretanto, nesse tipo de interpretação, os agentes ficavam destituídos daquilo que atrai os cientistas sociais, vale dizer, da sua capacidade de interpretar, de conferir significado a partir de distintas esferas da sua experiência.Estavam reduzidos à forma simples, elegante, mas abstrata que os aprisionava, primeiro, na dinâmica da vida econômica e, segundo, no suposto da racionalidade como fundamento exclusivo para a sua conduta.

Ora, se as características das condições da concorrência perfeita, como transparência, permeabilidade, homogeneidade, mobilidade, entre outras, têm sido postas em questão pela moderna sociologia dos mercados, porcerto elas são de duvidosa prevalência eaplicação imediata sobretudo nos mercados por onde circula o trabalho34, uma "mercadoria fictícia", sequisermos lembrardos ensinamentos instigantes de Polanyi.

Essa agenda teórica de pesquisas mostra-se particularmente elucidativa quando a tomamos em conta para entender realidades como a de mercados de trabalho estruturalmente flexíveis, pouco regulados, com forte peso de relações informais, e marcadamente desiguais em termos dos seus sistemas de estratificação, como é o caso das grandes metrópoles latino-americanas.

Como opera um mercado de trabalho assim constituído? Como, nele, os mecanismos mercantis e não-mercantis se combinam, conferindo-lhe especificidade? Para bem entendê-lo, nada como ilustrar, o que farei doravante, lançando mão de resultados do mais recente estudo empírico que desenvolvi e no qual busquei entender como se tem acesso à porta principal do mercado de trabalho.

Procurarei mostrar como são socialmente construídas as chances de obter as oportunidades ocupacionais e como, neste caso, mecanismos não mercantis são fundamentais e estão enraizados na dinâmica de relação entre indivíduo e mercado, mesmo quando observamos indivíduos que acorrem regularmente a instituições mercantis em sua busca de trabalho.

\section{A CONSTRUÇÃO SOCIAL dO ACESSO AO MERCADO DE TRABALHO}

Estimulada pelos insights da sociologia econômica e acreditando novalor heurístico dessa nova forma de ol har para o mercado de trabalho, desenvolvi, recentemente, um estudo voltado para entender como as oportunidades ocupacionais são postas ao alcance dos indivíduos,
[34] White, H.C. "Where do markets come from?". American Journal of Sociology, vol. 87, $\mathrm{n}^{\circ}$ 3, pp. 517- 87, 1981; Granovetter, M. "Economic action and social structure: the problem of embeddedness". American Journal of Sociology, vol. 91, $\mathrm{n}^{\circ}$ 3, pp. 481- 510, 1985; Idem, "The sociological and economic approaches to labor market analysis: a social structural view". In: Granovetter, M.e Swedberg, R. (eds.) The sociology of economic life. Boulder: Westview Press, pp. 233- 63, 1991; Garcia- Parpet, M. F."La construction sociale d'un marché parfait: le marché au cadran de Fontaines- enSologne". In: Actes de la Recherche en Sciences Sociales, Paris, 1986, pp. 5-10; Swedberg, op. cit.; Fligstein, op. cit.; Steiner, La sociologie économique, op. cit; Idem, "Le marché vu par la sociologie économique", op. cit.

[35] Trata- se do projeto "À procura de trabalho: instituições do mercado e redes", desenvolvido no Centro de Estudos da Metrópole (programa que reúne Cebrap, USP e Fundação Seade), e que contou com apoio do CNPq e da Fapesp/Programa Cepid.

[36] Embora pouco estudado entre nós, o tema tem sido tratado em outros contextos. No que concerne aos Estados Unidos, ver Peck, J. e Theodore, M. "O trabalho eventual: crescimento e reestruturação da indústria de empregos temporários em Chicago". Revista Latinoamericana de Estudios del Trabajo, ano 5, $\mathrm{n}^{\circ}$ 10, 1999. pp. 135-60. Benner, C., Leete, L. e Pastor, M. Staircases or treadmills? Labor market intermediaries and economic opportunity in a changing economy. Nova York: Russell Sage Foundation, 2007. No que diz respeito à Europa, ver Benarrosh, Y. "Tri des chômeurs et consensus des acteurs del'emploi:vers une approche des 'trappes d'inemployabilité"'. Travail et Emploi, $\mathrm{n}^{\circ} 81$, jan., 2000, pp. 9- 26; Kartchevsky, A. e Caire, G. Les agences privées de placement et le marché de travail. Paris: L'Harmattan, 2000; Forde, C. "Temporary arrangements: the activities of employment agencies in the UK", Work, Employment and Society, vol. 15, $\mathrm{n}^{\circ} 3,2001$, pp. 631-44; Beynon, H. e outros. Managing employment change: the new realities of work. Oxford: Oxford University Press, 2002; Gray, A. "Jobseekers and gatekeepers: the role of the private employment agency in the placement of the unemployed". Work, Employ- 
ment and Society, vol. 16, $\mathrm{n}^{\circ} 4,2002$, pp. 655-74; Bergstrom, O. e Storrie D. Contingent employment in Europe and the United States. Cheltenham: Edward Elgar, 2003; Koene, B. e Purcell, K. "The value of relationships in a transactional labour market: constructing a market for temporary employment", out., 2004, mimeo. No que concerne a países da América Latina, ver Echeverría, M. "Las empresas intermediarias en el mercado laboral".In:Díaz,X.e Hola, E.(orgs.). Trabajo, flexibilidad y género:tensiones de un proceso. Santiago: Centro de Estudios de la Mujer, 2001, pp.69-98.

[37] Granovetter. "The strength of weak ties". American Journal of Sociology, vol. 78, n 6, 1973, pp. 1361- 80; Idem, "Introduction". In: Getting a job: a study on contacts and careers. Cambridge: Harvard University Press, 1974,pp.3-22; Idem, "Economic action and social structure...", op. cit.; Idem, "The sociological and economic approaches...”, op. cit.; Lin, $\mathrm{N}$. Social capital: a theory of social structure and action. Cambridge:Cambridge University Press, 2001.

[38] Polanyi, K. A Grande Transformação. As origens da nossa época. Rio de Janeiro: Campus, [1944] 2000; White, H. "Matching vacancies and mobility". Journal of Political Economy, vol. 78, no 1, 1970, pp. 97105; Idem, "Where do markets come from?", op. cit.

[39] Swedberg, op.cit..

[40] "Introduction", op. cit. focalizando a dinâmica do mercado de trabalho sob o ponto de vista dos mecanismos acionados na saída do desemprego35.

Interessava-me conhecer uma dimensão particulare que especifica os grandes mercados de trabalho, ainda que muito pouco estudada entre os cientistas sociais, o mercado de intermediação de oportunidades ocupacionais. Assumia o desafio de refletir sobre as diferentes formas de enraizamento (embeddedness) extra-econômico na construção das relações entre os três agentes nesses grandes mercados de força de trabalho: os demandantes de emprego, as empresas que recrutam trabalhadores e os intermediadores entre oferta e demanda de trabalho (agências de emprego e empresas de trabalho temporário) ${ }^{36}$.

Acreditava que em grandes mercados metropolitanos nos quais confluem, de um lado, intensa reestruturação das atividades produtivas e flexibilização crescente das relações e das condições de uso do trabalho e, de outro, elevado desemprego recorrentemente manifesto nas trajetórias ocupacionais dos indivíduos, ganhariam importância as instituições especializadas na intermediação de oportunidades ocupacionais.

Entretanto, sabemos que o acesso a oportunidades de trabalho muitas e muitas vezes se resolve por meio de mecanismos que escapam à racionalidade e às instituições especializadas do mercado, $e$ passa pelas redes tecidas pelos indivíduos em suas distintas esferas de sociabilidade no curso da vida cotidiana. A esse respeito, o debate sobre o acesso às oportunidades de trabalho, e em particular sobre a circulação de informações no mercado de trabalho, é devedor das formulações de dois autores, Mark Granovetter e Nan Lin37.

Granovetter, seguindo pistas tão diversas quanto as de Polanyi e White ${ }^{3}$, sugeriu - e documentou empiricamente - que a criação e a evolução de um mercado (aí compreendido o mercado de trabalho) dependeriam de certo número de condições sociais e políticas que contribuiriam igualmente ao seu funcionamento, o que Swedberg 39 posteriormente denominaria "estrutura social do mercado".

No caso das oportunidades ocupacionais, ou da procura de trabalho, por exemplo, haveria que ter em conta os "contatos" a partir dos quais as pessoas se tornavam sabedoras da informação pertinente, mesmo quando elas não estivessem disponíveis no mercado, em busca de uma ocupação. Assim, ao entrevistar chefias e quadros mais altamente qualificados em seu famoso estudo, Granovetter ${ }^{\circ 0}$ deu-se conta de que o encontro entre demandantes e ofertantes de trabalho não era nada trivial e poderia se realizar por diferentes tipos de mecanismos, dentre os quais destacou três: os procedimentos impessoais (como anúncios e agências de emprego), as candidaturas espontâneas (via prospecção direta junto aos empregadores) e os contatos pessoais. Pouco mais que cinco em cada dez indivíduos por ele investigados 
reconheciam nos contatos pessoais, e não nos mecanismos mercantis, a grande via para localizar oportunidades de trabalho.

Em estudo que realizei em 2001 na região metropolitana de São Paulo, indagados em survey domiciliar por amostra representativa da $\mathrm{PIA}^{41}$, nada menos que sete em cada dez indivíduos consideravam as informações obtidas junto a familiares, amigos e conhecidos como sendo a forma mais corrente de buscar trabalho; além disso, esta era a forma que (em mais da metade dos casos) se mostrara efetiva para a obtenção do último emprego. E embora o peso dos mecanismos institucionais e dos circuitos impessoais se mostrasse bem maior ali do que em Paris e Tóquio, duas outras metrópoles também investigadas, não era descartável a importância dos contatos pessoais também nessas duas outras metrópoles; entretanto, era em São Paulo onde esses contatos adquiriam notável relevância ${ }^{42}$. E estes não provinham apenas dos chamados "elos fracos", como fora documentado por Granovetter ou por Degenne e Forsét3.

Posteriormente, em novo survey conduzido em $2004^{44}$, pesquisei mais detidamente uma amostra representativa daquele grupo de indivíduos que dizia procurar regularmente trabalho em agências de emprego, ou seja, via as instituições do mercado de trabalho. Eles eram minoria, representando apenas três em cada dez pessoas no levantamento que conduzi em 2001 , mas, apesar disso, me debrucei sobre eles, em nova pesquisa. E, de fato, quando indaguei a esses indivíduos amostrados no novo estudo sobre como costumavam procurar trabalho, respondiam de modo avassalador que o faziam através das instituições de intermediação do mercado.

Entretanto, e para minha surpresa, quando analisados os últimos empregos por eles obtidos, um número igualmente avassalador respondia tê-los localizado não através das agências onde procuravam, mas das suas próprias redes. No mais das vezes, eram redes formadas pelo circuito familiar (não necessariamente domiciliar) e de vizinhança; os mais velhos, e com maior experiência no trabalho, tinham nos contatos profissionais, nos antigos colegas, fontes eficazes para lhes levar a obter novos empregos45. Mas observei também que era precária a qualidade dos empregos obtidos através dos circuitos de maior proximidade; eles duravam pouco e produziam inserção de baixo prestígio se comparados aos empregos obtidos através dos circuitos profissionais de circulação da informação.

Qual a importância desses achados e reflexões para um estudo sobre a operação do mercado de trabalho e, mais exatamente, sobre as oportunidades de saída do desemprego? Eles sugerem que nem todos os indivíduos têm igual acesso às informações ocupacionais pertinentes e, nesse sentido, nem todos se beneficiam de modo igual de suas redes de relações. Porvezes, porque a rede à qual têm acesso é menos eficaz em
[41] Trata- se da pesquisa "Desemprego: abordagens institucional e biográfica. Uma comparação São Paulo, Paris, Tóquio", conduzida no Centro de Estudos da Metrópole em parceria com a Fundação Seade. Foi levado a campo um questionário suplementar à Pesquisa de Emprego e Desemprego - PED, entre abril e dezembro de 2001, recobrindo uma amostra de cerca de 50 mil pessoas, formada por aproximadamente 7 mil desempregados, 16 mil inativos e 36 mil ocupados. Para mais detalhes, ver Guimarães, N. A. Desemprego, uma construção social: São Paulo, Paris, Tóquio. Belo Horizonte: Argvmentvm, 2009.

[42] Guimarães e outros. "Desemprego - mercados, instituições e percepções: Brasil e Japão numa perspectiva comparada". Tempo Social, vol. 16, no 2, 2004, pp. 257- 87; Guimarães. "Unemployment and occupational transitions: trajectories and perceptions". In: Kase, K. e Sugita, K. (orgs.). The unemployed and unemployment in an international perspective: comparative studies of Japan, France and Brazil. Tokyo: The University of Tokyo/Institute of Social Sciences, 2006, pp. 42- 67; Guimarães, Desemprego, uma construção social..., op. cit.

[43] Granovetter. "The strength of weak ties", op. cit.; Idem, "Introduction”, op. cit.; Degenne, A. e Forsé, M. Les réseaux sociaux. Paris: Armand Colin, 1999, caps.1- 2, pp. 5-76.

[44] Trata- se do survey "À procura de trabalho", já referido anteriormente.

[45] Guimarães. "Como sair do desemprego? Laços fortes e laços fracos na procura de trabalho em São Paulo". Comunicação ao IX Congresso da Brasa - Brazilian Studies Association, Tulane University, New Orleans, USA, em 27- 29 mar. 2008. 
termos da informação que nela circula; outras vezes porque sua própria posição na rede lhes é menos favorável que a outras pessoas.

Mas, observando de maneira mais acurada estes resultados eles indicam que a articulação entre ofertantes e demandantes de trabalho está longe de ser automática, e nem mesmo se realiza por mecanismos unicamente mercantis de difusão da informação; ela é, e em grande medida, um subproduto de outras relações sociais que não têm uma dimensão mercantil. O funcionamento do mercado de trabalho, como de resto de outros mercados, demanda, assim, que estruturas sociais subjacentes sejam examinadas de maneira a se compreender as formas de transmissão de oportunidades. Nesse sentido, fica evidente que se trata de um processo que não se resume a mecanismos usuais de coordenação mercantil via sistema de preços (no caso o preço pelo qual se admite trabalhar ou, visto por outro ângulo, o preço pelo qual se aceita recrutar um trabalhador).

A análise das redes pessoais, ao modo do que sugerem os estudos de Mark Granovetter e Nan Lin, é certamente uma via para flagrar o processo pelo qual se estrutura o acesso a ocupações. Uma via instigante, como vimos, e que nos permite ir além do que até aqui tradicionalmente fazia a sociologia do trabalho quando retratava os resultados da operação do mercado de trabalho, expressos na dinâmica da estrutura do emprego.

Mas, os insignts desta nova sociologia econômica permitem levar um pouco mais longe a agenda de estudos do mercado de trabalho, no que concerne aos mecanismos mobilizados para se ter acesso a um emprego.

Isto porque, a procura de trabalho não é um empreendimento simples, como poderia parecer a primeira vista, pautado por certo voluntarismo do demandante de emprego. Conquanto tal voluntarismo pudesse parecer evidente, a um olhar apressado, nas próprias respostas daqueles que encontramos, buscando ativamente oportunidades de trabalho em agências de emprego, a análise qualitativa das interações que transcorriam na situação de procura de trabalho deixou entrever o longo caminho que por vezes tinha que ser percorrido para bem qualificar-se como um "demandante de emprego". Assim, não basta estar desempregado para habilitar-se e ser reconhecido como um "bom demandante de emprego".

Isto porque não é nada trivial estar no mercado à procura de trabalho. Quando escasseiam as vagas, flexibilizam-se os momentos e as condições em que estas são oferecidas, bem como se elevam os requerimentos para ocupá-las e abundam os indivíduos que as almejam. Nessas condições, as empresas, em sua busca incessante da focalização racionalizadora, externalizam seus antigos encargos de localizar e triar candidatos. Intermediários passam a atuar nesses grandes e opacos mercados fazendo a primeira seleção de pretendentes, de sorte 
que o core do setor de RH das empresas usuárias apenas define os perfis almejados e bate o martelo sacramentando a decisão, após apreciar unicamente os candidatos mais competitivos e perfeitamente aderidos a tal perfil.

A empresa não quer despender custos nesse processo; e, ao contratar um intermediador da sua relação (de triagem e/ou contratual e/ou de supervisão) com aqueles a quem emprega, tampouco aceita que tal agenciador se equivoque, enviando-lhe um pretenso trabalhador que não cabe no figurino ou que, uma vez em atividade, não manifeste as características que levaram ao seu recrutamento.

Assim, nesse novo contexto, espera-se a "melhor performance" tanto do trabalhador a ser contratado, como da agência de empregos ou da empresa de trabalho temporário que o triou. Para estas últimas, o melhor desempenho do candidato indicado é condição para a boa apreciação da sua própria performance como fornecedora de trabalho e, logo, de continuidade da relação de serviço que as une à empresa usuária. Fidelização buscada, paradoxalmente, em meio ao torvelinho da flexibilidade crescente, tal como Koene e Purcell46 já haviam sugerido.

Ora, assim sendo, não basta estar desempregado, ou à procura de trabalho, para "naturalmente" ser considerado habilitado a ocupar uma vaga. Para melhor compreender esse processo de legitimação do indivíduo como demandante de trabalho, como um possível empregado, todo um percurso no mercado de intermediação tem lugar.

Arriscaria dizer que nosso conhecimento acadêmico sobre a existência e a natureza de tal percurso, ao menos como documentado na literatura sociológica brasileira, era, até aqui, virtualmente nulo. Por conta disso, dirigi um trabalho de equipe, voltado à observação sistemática, próxima ao estilo das etnografias que tanto gosto fazem aos antropólogos do trabalho. Neste estudo, procuramos esquadrinhar a operação do mercado de trabalho tomando um ponto de partida - o da situação de procura de trabalho. Esta foi reconstruída a partir da observação sistemática e voltada a flagrar diversos pontos de vista: o do desempregado em procura, o do preparador de currículos, o da recepcionista da agência de empregos, o da selecionadora de candidatos, o dos "homens-placa" que veiculam no próprio corpo oportunidades de trabalho.

Ao fazê-lo, foi possível identificar a diversidade de procedimentos e de regras de conduta que permitem ao indivíduo em situação de desemprego construir-se, representar-se e ser percebido como um demandante digno de habilitar-se a uma vaga no mercado de trabalho.

Tomamos como espaço de observação o cluster dos intermediadores situado no chamado "centro novo" da cidade de São Paulo, também conhecido como "o quadrilátero da Barão" (por referência à rua Barão de 
[47] Guimarães. "Empresariando o trabalho: os agentes econômicos da intermediação de empregos, esses ilustres desconhecidos". Dados, vol. 51, n' 2, 2008, pp. 275-311.

[48] Callon, M. "Introduction: the embeddedness of economic markets in economies". In: The Laws of the Markets. Oxford: Balckwell, 1998, pp. 1- 57.

[49] Entretanto, de muito pouco adiantam os avanços nessa direção se eles não se complementam com uma mobilização integrada das outras funções: a (re)qualificação e sobretudo a captura das vagas que podem permitir a recolocação. Efetivamente, o sistema mantido com recurso público é tão bem organizado para mapear o demandante quanto mal aparelhado para localizar a vaga que poderá acolhê- lo. Justamente essa característica cria a condição de possibilidade para a paradoxal aproximação e eventual complementariedade de interesses e esforços entre ambos.
Itapetininga eadjacências). Essaescolha sefez depois de procedimentos prévios de análise quantitativa que georeferenciaram as agências (privadas e mantidas pelo recurso público) no espaço do município.

Tal processo de "construção social do demandante de trabalho", como referirei doravante, é perceptível com maior nitidez justamente quando analisamos os agentes privados do mercado de intermediação. Tal como desenvolvi mais detalhadamente em outra ocasião47, uma sorte de rationale operacional diferenciaria (e paradoxalmente aproximaria) os intermediadores privados, de um lado, e os mantidos pelo recurso publico (agências do governo e do sindicato), de outro. Enquanto os primeiros são bons captadores de vagas, os últimos parecem especializados em atrair demandantes de emprego. Por isso mesmo, as situações de procura de trabalho variam se observadas do ponto de vista das agências privadas ou das agências mantidas pelo recurso público. Para o entendimento do processo de "construção social do bom demandante de emprego", o contexto da procura em agências privadas é particularmente elucidador. Por que?

Retomo esse ponto, como um parênteses esclarecedor, antes de seguir adiante. Faço-o na esteira da abordagem proposta por Callon ${ }^{48}$, que ressalta o valor heurístico de entendermos as ações econômicas sem desprezarmos as tecnologias e os artefatos específicos que formam parte da situação em que elas transcorrem. Vejamos como umas e outras se apresentam nas situações de procura de trabalho.

Os sistemas governamental e sindical de intermediação de empregos, particularmente o primeiro, são muito bem-sucedidos em capturar e identificar aquele que necessita de trabalho. Por isso mesmo, entre os que são financiados pelo recurso público (FAT), há um notável ganho de qualidade com relação ao acesso e ao mapeamento dos demandantes. $O$ mesmo pode ser dito com respeito aos modos de acolhida e ao tratamento conferido ao individuo em busca de trabalho. Um elevado investimento em infra-estrutura tem lugar, sustentado por um sistema de informação de excelente qualidade, que requer para sua operação um corpo de funcionários capacitados (no manejo do sistema e na condução da entrevista para coleta de dados do demandante), além de espaço físico amplo e de investimentos diversos no layout das agências. Tudo isso (propiciado pelo recurso público) assegura a recepção e o processamento das demandas dos desempregados em bases altamente profissionais e tecnicamente refinadas, como no caso de algumas agências do circuito sindical, que chegaram mesmo a especializar espaços para acolher demandantes de qualificação de nível superior, de modo a lhes ajudar a ultrapassar a vergonha associada não apenas à procura de emprego, mas às condições socialmente humilhantes em que tal procura costuma fazer-se (grandes filas, formadas à madrugada, em busca de senhas) 49 . 
Já as agências de emprego privadas e as empresas de trabalho temporário têm a sua rationale operacional, como vimos, movida não tanto pelo intuito de fidelizar o demandante, mas pelo intuito de fidelizar a empresa usuária, a que contrata os seus serviços para preencher vagas. Sua performance será tanto mais bem sucedida quanto maior for o número de empresas clientes e quanto mais rápida e eficiente for sua capacidade deencaminhar candidatos potencialmente recrutáveis ou de prover de trabalhadores subcontratados a empresa "tomadora dos seus serviços". Mas, em sua grande maioria, e notadamente entre as de pequeno e médio porte, essas empresas fazem baixíssimos investimentos no que concerne à captura de demandantes, os quais lhes chegam por gravidade, dado o efeito inercial do grande e recorrente desemprego.

Chegando por gravidade - e em grandes números — tais demandantes devem saber apresentar-se aos intermediários privados da maneira mais apropriada possível, conformes com as regras de reconhecimento de um potencial candidato, pret-à-porter do ponto de vista da triagem e do encaminhamento. Para tal, requer-se um modo adequado de agir e de apresentar suas qualificações, habilidades e pretensões. Apresentar-se conforme essa regra é obrigação do desempregado de sorte a maximizar as chances de ser reconhecido. Os custos, pessoais.

Essa regra começa com a apresentação de si:limpo, "condignamente" trajado e sobretudo portando um curriculum vitae impresso e construído de molde a ser facilmente esquadrinhado pela funcionária encarregada da recepção, sempre desafiada a realizar muito rapidamente a primeira triagem. Do êxito nesse primeiro momento depende a sobrevivência do candidato no segundo passo, qual seja, ser considerado digno de passar à retaguarda da agência, depois de apresentar pretensões de trabalho e de salário cabíveis com alguma das oportunidades ofertadas $5^{50}$. Somente vencida essa primeira barreira é que o processo de seleção se inicia, ao menos no que concerne àquela sua parcela visível ao senso comum. Entretanto, tal processo começou muito antes, por duas razões principais.

Primeira, porque estamos num mercado fortemente heterogêneo, onde são recorrentes as trajetórias despadronizadas, fragmentárias e, no caso dos jovens (significativos neste tipo de procura via instituições do mercado), os percursos marcados pela escassa experiência de trabalho, notadamente aquela que mais conta, a registrada em carteira.

Segunda, porque tal mercado se enraíza num contexto de enorme desigualdade social e elevada pobreza. Com isso, falta aos indivíduos as precondições para se apresentarem na situação de procura como "bons demandantes de trabalho". Assim, do ponto de vista do seu elo com a estruturação do mercado de trabalho, falta à maior parte desses demandantes a biografia ocupacional almejada pelos ofertantes
[50] Cabe à recepcionista o primeiro interrogatório, caso haja compatibilidade entre ocupação ofertada e pretensão de trabalho. Algumas perguntas- chave, entre as quais se sobressai a pretensão salarial, e uma rápida e certeira olhada no currículo podem decidir se o candidato segue adiante imediatamente (para entrevista e/ou as correntes dinâmicas de grupo), se seu currículo é lançado no grupo daqueles que podem ser tomados em conta (sendo ele chamado em seguida) ou se é lançado a um lote de outros tantos que, embora aparentemente armazenados, aos olhos do candidato que se retira contente, tem como destino a cesta do lixo ou um estoque ao qual por muito tempo ninguém recorrerá. 
de vagas. Ademais, grande parte deles sequer tem o capital cultural para suprir os requisitos de apresentação de si: não têm currículo, alguns sequer sabem do que se trata; outros, se o sabem, não operam computadores e não teriam condições prepará-los, já que lhes faltam os meios materiais para dispor de um computador e de uma impressora, de modo a dar ao currículo a forma impessoal e profissional queé condição sine qua non para apresentar-se diante da recepcionista numa agência privada.

Assim sendo, e avanço uma hipótese a partir dessa pista, num mercado tão heterogêneo e fortemente instabilizado pelo desemprego recorrente, onde se contraíam, no momento da minha pesquisa, os postos preenchidos conforme a velha norma (e o sempre atual desejo) - a do trabalho formal, "registrado em carteira", "fichado" - , e, a par disso, tão profundamente marcado pela desigualdade e pobreza, o processo de construção social do demandante de emprego, momento primeiro da caracterização da procura de trabalho, passa a ser um nicho onde se estabelecem outros agentes intermediadores, outras firmas, ou "quase-firmas".

Agentes precários (muitas vezes) e que intermedeiam não propriamente informações sobre oportunidades de trabalho, mas conhecimentos e procedimentos para que o atual desempregado (e potencial demandante) possa bem apresentar-se e ser reconhecido como um demandantelegítimo, habilitando-se a ter acesso à informação sobrevagas eapleiteá-las.Pequenos empreendimentosque concebeme "produzem" currículos e/ou que os reproduzem são o ponto de passagem inicial, que criam a necessidade de si, mercantilizando a realização de uma tarefa que em outros contextos sociais (nacionais ou de classe) seria parte da iniciativa individual do próprio trabalhador. Inexistindo tal possibilidade para muitos, há que entrar no mercado da intermediação pagando o preço de compra dessa mercadoria especial, passaporte quase mágico, o currículo digno e impresso em tantas vias quantas se alcance comprare distribuir. É ele que estabelece o mínimo denominador comum formal aos desempregados (pobres, a maioria) que querem adentrar à procura de trabalho nas agências privadas de emprego.

No caso dos desempregados de classe média, cuja procura já se faz pelos meios eletrônicos, muitas agências virtuais põem à disposição da pessoa que as acessa um serviço (com freqüência pago, como parte de um pacote) de preparação e/ou revisão do currículo, que toma como ponto de partida o formulário preenchido com perfil e pretensões no momento da inscrição no sítio internet da agência virtual de empregos.

O processo de construção do currículo é ele próprio um veio rico para se intuir sobre o imaginário social acerca do que deve ser um "bom demandante" de emprego, representações postas em ação pelo trabalho profissional dos intermediadores, que procuram "bem ves- 
tir" o demandante com as características que o mercado pretende neles encontrar. Compromisso, proatividade, envolvimento, interesse em aperfeiçoar-se, toda a cesta de atitudes que a literatura gerencial sobre os novos ambientes reestruturados imputa aos trabalhadores que neles podem sobreviver reaparece agora, por assim dizer de fora para dentro, de modo a elevar as chances de admissão de um cliente cujo currículo se prepara e/ou cujo perfil se quer valorizar ${ }^{51}$.

Mas a construção social do "bom demandante" não para aí. Há que saber bem desempenhar na situação de entrevista, inicialmente na própria agência, de sorte a poder ser posteriormente enviado como um candidato viável à entrevista final na empresa usuária. Para tanto, todo um outro conjunto de mecanismos - que também progressivamente se mercantilizam - interpõe-se entre o trabalhador e as vagas pretendidas. Para os mais bem providos financeiramente é possível pagar por consultorias que os preparem para as entrevistas ou para as "dinâmicas" (como são corriqueiramente chamadas as sessões de dinâmicas de grupo).A mercantilização opera, assim, como um divisor de águas queé a um só tempo social e de classe.

As mais modernas empresas de intermediação, que já distam muito de serem apenas agências de emprego (as quais fazem apenas a circulação da informação e a triagem preliminar), atuam com uma variedade bem mais ampla de produtos; assim, por exemplo, elas desenvolvem serviços de "dicas", muitas vezes gratuitas, que operam como uma sorte de socialização antecipada do desempregado, que a elas já acorre, pela via da interação virtual, minimamente capacitado. Novamente, diante da abundância de oferta, a racionalização do seu trabalho pode se fazer transferindo algumas iniciativas para o trabalho autônomo de construção de si pelo desempregado.Écerto que isso supõe uma certa posição social e um certo capital cultural, sem os quais a autonomização carecerá de bases materiais e simbólicas.

Aqueles que não apresentam tais características podem ficar restritos às agências menos onerosas, provedoras de serviços menos complexos, intermediadoras de vagas de pior qualidade e muitas vezes localizadas em espaços tão recônditos (pelo alto custo de locação nas posições mais visíveis dentro dos clusters mais importantes) que o primeiro elo da cadeia de intermediação entre agência e demandante é ele próprio uma figura bizarra, novamente só cabível nos mercados (ou entre os indivíduos) sujeitos a intensa pobreza e desqualificação, os "homens-placa" ou "plaqueiros" 52 . Trabalhadores da intermediação, eles são a ponta mais avançada das pequenas agências, usando seu próprio corpo como stand de exposição das oportunidades cujo preenchimento a "sua" firma precisa intermediar. Misto destands, pessoas desprovidas de humanidade, são também agenciadores eficazes, circulando com as vagas em exposição justamente onde se acumu-
[51] Para uma análise rica em detalhes, ver Hirano, L. F. K. "Currículo: a embalagem do produto". In: Guimarães, N.A. (org.). A procura de trabalho - instituições de intermediação e redessociais na saida do desemprego: São Paulo numa perspectiva comparada. Relatório Final do Projeto CNPq, São Paulo, CEM/DS, 2007, cap. 7,pp. 189-229.

[52] Vieira, P. "O homem e a placa ou a placa e o homem? Os "homensplaca" e a procura de trabalho no Centro de São Paulo". In: Guimarães, À procura de trabalho..., op. cit., cap. 8 , pp. 229-50. 
lam os desempregados, numa surpreendente relação de trabalho que pode ter a durabilidade que o mercado nega à grande maioria dos seus trabalhadores. Senhores, no mais das vezes homens, com freqüência aposentados, eles expõem vagas em seus corpos por 5, 10, 12 anos, num laço ininterrupto com um tipo de ocupação, até aqui tão invisível aos estudos da sociologia do trabalho, quanto eles o são aos olhos dos desempregados que "os consultam".

Acredito que essa complexidade dos agentes e das condutas na situação de procura, particularmente visível quando a buscamos vislumbrar pelas lentes institucionalizadas das agências de emprego, serve para documentar o argumento-chave que me anima: o de que o entrecruze entre oferta e demanda de trabalho não é trivial, mas para fazer jus à riqueza da abordagem sociológica - ele precisa ser tratado como um processo, e não apenas pelo seu resultado (um quantum final de empregados ou de desempregados), como corriqueiramente tem sido feito nas análises (mesmo aquelas de natureza sociológica) acerca dos mercados de trabalho.

Nesse sentido, acredito ter ilustrado que, ao tomar a situação de procura como um objeto de investigação sociologicamente relevante para desvendar a dinâmica dos mercados de trabalho, é possível entrever como a obtenção de trabalho é um processo multifacetado em sua rica construção social. Mais ainda, este tipo de abordagem revelou o seu notável valor heurístico para desvendar novas configurações do trabalho e da sua circulação mercantil.

Analisá-las requer não apenas entender, como fazem mais das vezes os economistas ou uma certa microsociologia do trabalho, a dinâmica das firmas em seus movimentos de reestruturação e de absorção do trabalho. Nem mesmo como tradicionalmente tem feito a sociologia do desemprego - ao pesquisar o trabalhador individual em busca de ocupação - indagando por seu tempo de procura de trabalho, seu perfil e pretensa empregabilidade, de modo a desvendar a seletividade do processo ou o sofrimento subjetivo que a ele se associam. Se estes são certamente aspectos importantes, eles não são suficientes para bem compor uma agenda para a sociologia dos mercados contemporâneos de trabalho.

Abrir a caixa preta do encontro entre ofertantes e demandantes de trabalho, penetrar no coração daquilo que se define como o mercado de força de trabalho torna-se, então, uma dimensão analítica crucial.E, ao mesmo tempo, um exemplo de como uma análise sociológica dos mercados de trabalho pode se erigir com base numa agenda autônoma que não a reduza (ou subsuma), como antes, seja à sociologia das desigualdades e da estratificação social, seja à sociologia das ocupações, seja à sociologia industrial e das organizações, ou mesmo à sociologia do desenvolvimento, para não falarmos da economia do trabalho. 
A observação da situação de procura, das instituições que ali se apresentam, das performances que nela têm lugar e das redes que sustentam a efetiva obtenção da ocupação é, assim, um exemplo de como se pode restabelecer o sentido forte da análise sociológica do mercado de trabalho. Uma reflexão compreensiva sobre relações sociais situadas, isto é, socialmente construídas, capaz de revelar como operam os mercados contemporâneos de trabalho em sua diversidade estrutural e institucional, material e simbólica.

NADYAARAUjo GUIMARÃES é professora titular do Departamento de Sociologia da Universidade de São Paulo e pesquisadora do CNPq associada ao Centro de Estudos da Metrópole.

Recebido para publicação

em 7 de março de 2009 .

\section{NOVOS ESTUDOS}

CEBRAP

85 , novembro 2009

pp. $151-170$ 